\title{
Pengaruh Current Ratio(CR), Return On Equity (ROE), Debt To Equity Ratio (DER)Terhadap Harga Saham (Pada Perusahaan Manufaktur yang Terdaftar di BEI Periode 2015-2018)
}

\author{
Dhawi Ardy Wibowo ${ }^{1}$, Moh Afrizal Miradji ${ }^{2}$, Ulfa Puspa Wanti Widodo ${ }^{3}$ \\ Universitas PGRI Adi Buana Surabaya1,2,3 \\ dhawiardy89@gmail.com
}

\begin{abstract}
ABSTRAK
Produk adalah sertifikat kepemilikan perusahaan, dan pemegang saham berhak mengklaim pendapatan dan aset perusahaan. Motif penelitian ini adalah untuk mengetahui pengaruh Current Ratio (CR), Return on Equity (ROE), dan Debt to Equity (DER) persentase Indonesia secara bergantian selama 2015-2018. Simak metode kuantitatif yang digunakan, sebuah contoh ditemukan oleh 10 produsen pada 2015-2018. Kumpulan record menggunakan beberapa jejak regresi. pada pendapatan (ROE) dan debt to income ratio (DER) terpengaruh dan pada saat yang sama berdasarkan total share charge dari grup-grup yang terdaftar pada perdagangan saham Indonesia tahun 2015-2018.

Kata kunci: Current Ratio, Return On Equity, Debt To Equity Ratio, Harga Saham
\end{abstract}

\begin{abstract}
The product is a certificate of ownership of a company, and shareholders are entitled to claim the income and assets of the company. The motive of the take a look at became to discover the effect of current medium (CR), return on money (ROE), and debt-to-finance (DER) Indonesia's percentage alternate in the course of 2015-2018. The have a look at used quantitative methods, an instance discovered by means of 10 producers in 2015-2018. The records sets used a couple of regression traces. on income (ROE) and debt to income ratio (DER) were affected and the same time based totally on the share charge of the groups listed at the Indonesia stock trade at 2015-2018.
\end{abstract}

Keywords: Current Ratio, Return On Equity, Debt To Equity Ratio, stock prices

\section{PENDAHULUAN}

Harga saham adalah nilai kapitalisasi pasar saham. Nilai suatu produk artinya faktor krusial dan wajib diperhitungkan ketika berinvestasi, sebab harga produk mencerminkan pencapaian pemasok. Tren harga di pasar terdiri berasal tiga kategori: porto tinggi (biaya lebih tinggi), lebih murah (biaya lebih rendah) serta hanya biaya (harga penutupan). Nilai tertinggi serta terendah merupakan yg tertinggi atau terendah, terjadi pada hari bursa. insiden harga saham terjadi pada akhir periode pertukaran (Egam, Ilat dan Pangerapan 2017).

Rasio likuiditas yang mewakili itu adalah rasio likuiditas saat ini (CR). CR ini menunjukkan kinerja perusahaan dalam memenuhi kewajiban utang saat ini. Selain rasio likuiditas, ada juga rasio profitabilitas. Return on equity (ROE) adalah nilai tukar yang harus diberikan lebih dari perusahaan yang mengelola modal sendiri (modal) dengan menghitung tingkat pengembalian investasi. Di 2015 ada lebih sedikit orang atau mitra, Jika memiliki pengembalian investasi yang rendah, maka perusahaan tersebut tidak terwakili dengan baik. Ini akan mempengaruhi selera risiko pemegang saham, oleh karena itu, untuk mendapatkan bunga pemegang saham, perlu untuk mengamati rasio modal agar memiliki tingkat yang baik. Lebih banyak produk tradisional dan lebih baik (SUjarweni, 2017: 65).

Rasio solvabilitas adalah rasio kedalaman terhadap ekuitas (DER), di mana rasio ini memperhitungkan berapa banyak perusahaan menggunakan utangnya. Berdasarkan penjelasan ini, dapat dilihat bahwa rasiorasio ini dapat menggambarkan tingkat kinerja perusahaan. Di mana perusahaan dapat meningkatkan 
kinerjanya, itu dapat menarik investor potensial yang kemudian berinvestasi di perusahaan. Ini akan mempengaruhi tingkat penawaran dan permintaan saham di pasar saham.

Berdasarkan pengungkapan di atas, dikatakan bahwa rasio ini menjelaskan tingkat kinerja keuangan perusahaan, semakin tinggi tingkat efisiensi dalam perusahaan, semakin menarik investor untuk menginvestasikan modalnya. Di mana perusahaan tersebut dipilih, perusahaan yang cukup besar dalam kaitannya dengan semua jenis kegiatan di bidang ekonomi dan kehidupan di masyarakat. Maka peneliti ingin meneliti dengan judul skripsi "pengaruh Current Ratio(CR), Return On Equity(ROE), Debt To Equity Ratio(DER) Terhadap Harga Saham (di Perusahaan Manufaktur yg Terdaftar di BEl Periode 2015-2018).

\section{TELAAH PUSTAKA}

\section{Penelitian Terdahulu}

Berdasarkan latar belakang penelitian dan pernyataan persoalan yang diajukan sebelumnya, peneliti mencoba memakai beberapa surat keterangan asal studi sebelumnya yang relevan menggunakan topik penelitian ini, berikut adalah merupakan pelukisan dari studi sebelumnya, termasuk:

Dwi Fitrianingsih serta Yogi Budiansyah (2018) akibat waktu Ini dan taraf Penghapusan Utang Terhadap Harga saham di Perusahaan kuliner serta Minuman yang Tertulis pada Bursa imbas Indonesia antara 20132017. Sedangkan Rasio Lancar Variabel Independen serta Rasio hutang terhadap ekuitas memiliki efek yang sama pada perubahan hargasaham.

\section{LANDASAN TEORI Current Ratio (CR)}

Rasio ini adalah koefisien untuk mengevaluasi efektivitas perusahaan dalam membayar utang saat ini, yang akan segera kedaluwarsa saat pengumpulan secara keseluruhan (Kasmir, 2017). Perhitungan CR yang lebih tinggi berarti bahwa utang kepada kreditor dapat dijamin. CR yang tinggi ini memaksa produsen untuk mempercayai perusahaan dan berinvestasi, karena perusahaan mampu melunasi hutang jangka pendeknya untuk meningkatkan permintaan akan saham. Selain itu, ini dapat berarti bahwa jika CR terlalu tinggi, itu berarti bahwa perusahaan memiliki kelebihan aset lancar, yang berarti bahwa tidak ada optimisasi manajemen untuk mengelola investasi dalam asetnya secara produktif (MAmduh,2016).

\section{Return On Equity (ROE)}

Return on equity artinya Pengembalian untuk mengukur laba bersih setelah pajak menggunakan ekuitas, (KAsmir, 2016: 204). Perbandingan ini menunjukkan kemampuan buat melakukan capital gain sesuai nilai pemegang saham. meningkat model ini, semakin baik, bahwa posisi pemilik perusahaan diperkuat. adalah krusial bahwa menjadi pengembalian investasi, laba bagi pemegang saham dibagi dengan jumlah kapital tersebut. Ukur kemampuan perusahaan buat mendapat untung dari pemegang sahamnya (Brigham \& Houston, 2016: 133).

\section{Debt To Equity Ratio (DER)}

Rasio DER menjelaskan hubungan antara jumlah pinjaman jangka panjang yang disediakan oleh debitur dan jumlah modal yang dibuat pemilik. Rasio solvabilitas artinya rasio yang memilih kemampuan perusahaan buat membayar kewajibannya Bila terjadi likuidasi (Darsono dan Ashari, 2015: 55). Indeks ini juga disebut rasio Leverage, yg mengukur batas pinjaman perusahaan. dengan demikian, porto rasio hutang terhadap pendapatan (DER) berarti "rasio utang terhadappendapatan ialah ukuran lain untuk memilih kemampuan perusahaan buat membayar utang." ialah, Koefisien DER menggambarkan rasio antara jumlah pinjaman jangka panjang yang diberikan oleh debitur dan jumlah modal yang dibuat oleh pemilik. (GIbson, 2018: 260).

\section{Harga Saham}

Sartono (2018: 70) berpendapat bahwa harga komoditas diciptakan oleh mekanisme penawaran dan permintaan pada pasar uang. ketika pasokan meningkat, harga saham cenderung meningkat. Atau, Jika persediaan tinggi, maka harga produk akan menurun. Jogiyanto (2018: 167) menyatakan bahwa nilai suatu komoditas, harga produk yg terjadi pada pasar komoditas selama periode ketika eksklusif, dipengaruhi oleh 
pedagang pasar dan berdasarkan di pasokan. dan permintaan untuk saham yg terkait menggunakan pasar kapital. "

\section{Kerangka Konseptual}

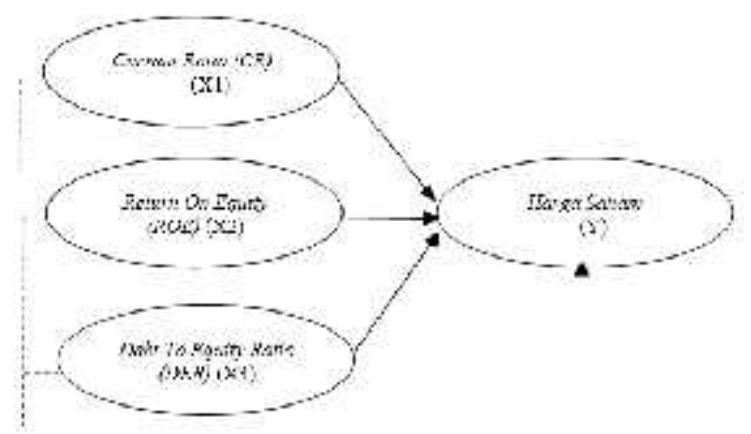

sesuai penerangan pada latar belakang, pernyataan persoalan, tujuan serta kegunaan penelitian, landasan teori, penelitian sebelumnya, serta landasan konseptual dan rumusan hipotesis, hipotesis bisa dirumuskan menjadi berikut:

$\mathrm{H} 1$ : current ratio $(\mathrm{CR})$ menghipnotis profitabilitas saham perusahaan manufaktur yg terdaftarpada Bursa efek Indonesia (BEI) di 2015-2018.

$\mathrm{H} 2$ : Return on equity (ROE) menghipnotis pengembalian saham perusahaanmanufaktur yg terdaftar di Bursa efek Indonesia (BEI) pada 2015-2018.

H3: Rasio hutang terhadap ekuitas (DER) mensugesti pengembaliansaham perusahaan manufaktur yang terdaftar di Bursa dampak Indonesia (BEI) pada 2015-2018.

H4: Rasio likuiditas ketika ini (CR), laba secara simultan menghipnotis pengembalian saham perusahaanmanufaktur yg terdaftar di Bursa impak Indonesia (BEI) pada 2015-2018.

\section{Teknik Analisis Data}

Analisis data yang digunakan buat merampungkan duduk perkara yang diangkat padapenelitian ini merupakan menggunakan melakukan analisis regresi. isu ini menggunakan teknik yang digunakan untuk melakukan penelitian pula. Penggunaan metode analitis dibuat buat menentukan apakah ada hubungan sebab dampak antara variabel independen (variabel dependen) serta variabel dependen (variabel dependen). dalam penelitian ini, analisis regresi alami dilakukan.

\section{HASIL PENELITIAN DAN PEMBAHASAN}

\section{Analisa Deskriptif}

Analisis data digunakan buat mengidentifikasi analisis fluktuasi, berdasarkan: rasio likuiditas (CR), arus kas (ROE), utang terhadap pendapatan (DER) serta harga produk. Penjualan dihitung dari statistik berikut: nilai min dan aporisma dan homogen-homogen, dan rentang normal. info jelas berasal seluruh item studi dapat dicermati pada tabel berikut. 
Tabel 1

Analisis statistik

Descriptlye Statistics

\begin{tabular}{|l|rr|r|rr|r|}
\hline & V & Min & Max & Sum & Mean & $\begin{array}{c}\text { Sld. } \\
\text { Deviatio } \\
\text { n }\end{array}$ \\
\hline Current Ratio & 40 & .35 & 0,71806 & 102.85 & 38.197 & .10701 \\
Return On Equity & 40 & 068 & 45.59 .00 & 419.654 & 14.542 & .25482 \\
Debt'lo Equity Ratio & 40 & .11 & 0,90069 & 122.72 & 4.540 & 121.950 \\
Harga Saham & 40 & 0 & 1.3674 & 119270 & 4417 & 333.666 \\
Valid Y (listwise) & 40 & & & & & \\
\hline
\end{tabular}

Sumber diolah dari matput SPSS versi $16(2020)$

Berdasarkan hasil pengujian statistik deskriptif dengan SPSS Ver. 16 dalam tabel 4.2 menunjukkan bahwa:

1. Rasio saat ini (X1) memiliki nilai rendah 0,35 dan maksimum 16,74 dengan rata-rata 3,8197 dan standar deviasi 0,10701.

2. Return On Equity (X2) memiliki harga rendah 0,068 dan harga tinggi 45,59 dan nilai rata-rata 14,542 dan nilai unik 0,2548

3. Debt To Equity Ratio (X3) dengan nilai rendah 0,11 dan harga tinggi 20,97 dan nilai rata-rata 4,540 dengan standar deviasi 1,219

4. Variabel harga saham $(\mathrm{Y})$ memiliki rata-rata 0 dan rata-rata 13674 dengan rata-rata 4417 dan standar deviasi 1,219.

\section{Uji Regresi Linier Berganda}

Analisis statistik dan pengujian hipotesis pada penelitian ini memakai analisis regresi. Rahmawati, $\mathrm{A}$ et al (2012) menunjukkan bahwa penggunaan contoh regresi linier berganda digunakan buat menganalisis efek dua variabel independen $(X)$ atau lebih tinggi di varians, dependen $(Y)$. dalam penelitian ini, analisis yg digunakan untuk mengurangi volatilitas penelitian buat mengetahui apakah terdapat pengaruh antara asumsi pasokan air waktu ini, untung atas ekuitas, rasio utang terhadap ekuitas serta harga saham. Pemrosesan data dilakukan menggunakan memakai aplikasi SPSS 16. pada proses analisis memakai regresi linier berganda, analisis akan diperiksa sang contoh (uji-F), pengujian parsial variabel (uji-t), dan pula akan diuji buat koefisien determinasi (R2). sesuai akibat analisis regresi linier berganda, hasil analisis dapat dilihat pada tabel pada bawah ini:

Tabel 2 .

Lji Regresi Liuier Berganda (Koefisien Determinasi)

\begin{tabular}{|r|r|r|r|r|}
\hline & & Model Summary \\
\hline Model & R & $\begin{array}{c}\text { R } \\
\text { Square }\end{array}$ & $\begin{array}{c}\text { Adjust } \\
\text { ed R } \\
\text { Square }\end{array}$ & $\begin{array}{c}\text { Std. Error } \\
\text { of the } \\
\text { listimate }\end{array}$ \\
\hline 1 & $.756^{\circ}$ & 571 & 166 & 304.770
\end{tabular}

Sumber diolah dari output SPSS versi 16 (2020). 
Tabel 3.

Uji Regresi Linier Berganda (Uji t)

Coefficients

\begin{tabular}{|c|c|c|c|c|c|}
\hline \multirow[b]{2}{*}{ Model } & \multicolumn{2}{|c|}{ Unstandardized Coefficients } & \multirow{2}{*}{\begin{tabular}{|r|}
$\begin{array}{l}\text { Standardized } \\
\text { Coefficients }\end{array}$ \\
Beta
\end{tabular}} & \multirow[t]{2}{*}{$t$} & \multirow[t]{2}{*}{ Sig. } \\
\hline & B & $\begin{array}{l}\text { Std. } \\
\text { Error }\end{array}$ & & & \\
\hline (Constanl) & 8.412 & 5.853 & & 1.437 & .827 \\
\hline Current Ratio & 2.094 & 2.211 & .117 & .947 & .024 \\
\hline Return On Lquity & 1.427 & 1.020 & .189 & 1.398 & .039 \\
\hline $\begin{array}{l}\text { Debt To Equity } \\
\text { Ratio }\end{array}$ & -.093 & 1.229 & -.011 & .075 & .044 \\
\hline
\end{tabular}

Sumber diolah dari output SPSS versi 16 (2020).

Tabel 4.

Uji Regresi I.inier Berganda (Uji F)

ANOVA

\begin{tabular}{|l|r|r|r|r|r|}
\hline Model & $\begin{array}{c}\text { Sum of } \\
\text { Squares }\end{array}$ & df & $\begin{array}{r}\text { Mean } \\
\text { Square }\end{array}$ & \multicolumn{1}{c|}{ Sig. } \\
\hline Regression & 99.943 & 3 & 19.989 & 2.152 & .014 \\
Residual & 222.923 & 36 & 9.288 & & \\
Total & 322.866 & 39 & & & \\
\hline
\end{tabular}

Sumber diolah dari output SPSS versi 16 (2020).

Berdasarkan hasil analisis yang ada pada tabel 4.18, didapat pula penurunan model regresi linier berganda sebagai berikut:

$$
Y=8,412+2,094 X_{1}+1,427 X_{2}+0,093 X_{3}+5,853
$$

Koefisien regresi variabel Rasio Lancar (X1) adalah 2,094, yang berarti bahwa jika Rasio Lancar dikalikan dengan 1 unit, harga saham akan mencapai peningkatan maksimal 2,094 unit. berarti ada hubungan langsung antara Rasio Lancar dan Harga Saham..

Koefisien regresi Return On Equity (X2) adalah 1,427, yang berarti bahwa jika Return On Equity bertambah 1 unit, Return On Equity meningkat secara signifikan, sebesar 1.427 unit.

Nilai koefisien regresi Debt to Equity (X3) adalah $-0,93$, yang merupakan tanda negatif bahwa ada perbedaan antara kesetaraan ekuitas utang dan harga komoditas.

\section{Uji Hipotesis}

\section{Koefisien Determinasi $\left(\mathbf{R}^{2}\right)$}

Menurut Wirawan (2012: 34), definisi berganda adalah bahwa semua titik terletak langsung pada garis regresi sampel, kemudian R2 $=1$. Dalam hal ini, mereka mengatakan bahwa itu cocok dengan sempurna. Tabel berikut menunjukkan hasil penentuan koefisien sebagai berikut:

\section{Tabel 5}

\section{Uji Koefisien Determinasi}

Modrl Summary

\begin{tabular}{|c|c|cr|r|}
\hline Model & $\mathrm{R}$ & R Square & $\begin{array}{l}\text { Adjusted R } \\
\text { Square }\end{array}$ & $\begin{array}{c}\text { Std. Error of } \\
\text { the Estimate }\end{array}$ \\
\hline 1 & $.756^{\mathrm{a}}$ & .571 & .166 & 3.04770 \\
\hline
\end{tabular}

Sumber diolah dari output SPSS versi 16 (2020)

menurut tabel 4.10. Nilai koefisien korelasi berganda $(R)$ yang diperoleh dari persamaan regresi linier 
berganda pada tabel di atas adalah 0,571 , karena masih ada korelasi moderat antara semua variabel independen $(X)$, termasuk rasio likuiditas saat ini, rasio pengembalian modal, rasio utang terhadap modal dengan menggunakan variabel dependen $(Y)$ adalah harga saham

berasal akibat data simulasi SPSS, nilai R (R2) ialah 0,571, yang berarti akurasi. Ini berarti bahwa $57,1 \%$ dari variabel Harga Saham bisa dijelaskan sang tiga investor independen termasuk Rasio Lancar, Imbal hasil Ekuitas, Rasio Hutang Terhadap Ekuitas, sedangkan 42,9\% lainnya didefinisikan sang orang lain faktor pada luar sampel atau pada luar penelitian.

\section{Uji Statistik t}

Tabel ?

t $\mathrm{ji} \mathrm{T}$

ANOVA

\begin{tabular}{|c|c|c|c|c|c|}
\hline Model & Sum or Squares & $\mathrm{ID \Gamma}$ & $\begin{array}{l}\text { Mean } \\
\text { Square }\end{array}$ & li & Sig. \\
\hline Regression & 99.943 & 3 & 19.989 & 2.152 & .014 \\
\hline Residual & 222.923 & 36 & 9.288 & & \\
\hline Tolul & 322.866 & 39 & & & \\
\hline
\end{tabular}

Sumber diolah dari output SPSS versi 16 (2020).

Dari hasil SPSS yg ditunjukkan pada atas, jelas bahwa:

1. Variabel "Current Ratio" memiliki nilai signifikan 0,024 di atas 0,05 , yg berarti bahwa rasio likuiditas saat ini secara parsial mensugesti harga saham.

2. dalam variabel Return On Equity, nilai 0,039 pada bawah 0,05 memberikan impak parsial Return On Equity terhadap harga saham.

3. pada variabel "Rasio Utang terhadap Ekuitas", nilai signifikannya merupakan 0,044 di bawah 0,05, yg berarti pengaruh parsial negatif dari rasio utang terhadap ekuitas terhadap harga saham.

Uji F

Tabel 6

tji parsial (1)

Coefficients ${ }^{\mathrm{a}}$

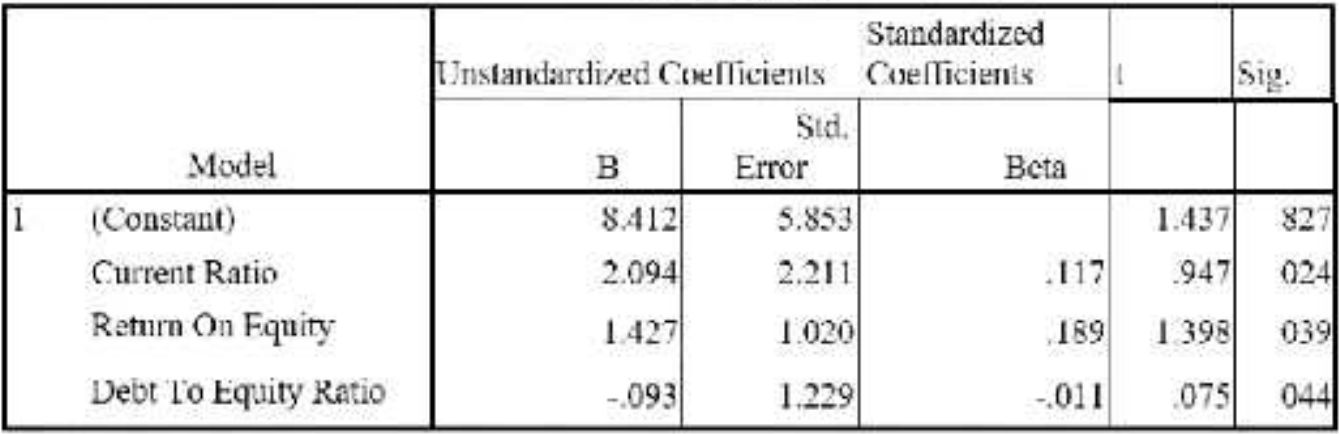

Sumber diolah dari output SPSS versi 16 (2020).

asal akibat menampilkan hasil SPSS, dapat dicermati bahwa: $F$ hitung dua,152 menggunakan taraf signifikan 0,014 di bawah 0,05, yg berarti bahwa variabel independen, terdiri berasal rasio likuiditas waktu ini, rasio return on equity, rasio hutang terhadap ekuitas, secara simultan mensugesti variabel dependen, yaitu harga saham.

\section{SIMPULAN}


Berdasarkan dari sekumpulan hasil uji statistik yang saya teliti menunjukan hasil yang signifikian dari 4 pengajuan hipotesis, dan ke-empatnya menujukan hasil hipotesis diterima secara signifikan positif dan signifikan negatif.

\section{Implikasi}

Dalam tes ini, diharapkan bahwa ia akan dapat memahami CR, ROE dan DER secara terpisah, dan pada saat yang sama mempengaruhi harga saham di perusahaan manufaktur BEI yang ada. Kehadiran tes ini membuktikan bahwa CR, ROE dan DER secara individual dan simultan memiliki efek. Terhadap harga saham di perusahaan manufaktur BEl yang ada.

\section{Keterbatasan penelitian}

Penelitian ini hanya menjelaskan sejauh variabel independen hanya menggunakan $C R, R O E$, dan DER, dan variabel dependen adalah harga saham dan periode waktu yang dibutuhkan 4 tahun untuk perusahaan manufaktur di bursa saham.

\section{DAFTAR PUSTAKA}

Brigham, Eugene F.; Joel F. Houston. 2014. Manajemen Keuangan Buku II. Edisi Kedelapan. Jakarta.

Darsono dan Ashari. 2015. Pedoman Praktis Memahami Laporan Keuangan. Cetakan Kedua. ANDI, Yogyakarta.

Egam, Ventje llat, Sonny Pangerapan. 2017)."Pengaruh return On Asset, Return On Equity, net profit Margin dan Earning PerbShare Terhadap Harga Saham Perusahaan yang tergabung dalam Indeks LQ45 di BEI Periode Tahun 2013-2015". Jurnal EMBA. Vol.5 No.1 Maret 2017, Hal. 105 - 114. Universitas Sam Ratulangi Manado.

Fitrianingsih, Dwi dan Budiansyah, Yogi. 2019. Pengaruh Current Rasio Dan Debt To Equity Ratio Terhadap Harga Saham Di Perusahaan Food And Beverage Yang Terdaftar Di Bursa Efek Indonesia Periode 2013 - 2017. Jurnal Riset Akuntansi Terpadu Vol.12 No.1, 2018 Hal. 144-166

Gibson 2018 Penilaian Kinerja. Penerbit Erlangga. Jakarta.

Hanafi, Mamduh M. dan Abdul Halim, 2014, Analisis Laporan Keuangan., Edisi tujuh., UPP AMP YKPN, Yogyakarta.

Hermawan, S., \& Amirullah. 2016. Metode Penelitian Bisnis: Pendekatan Kuantitatif \& Kualitatif. Media Nusa Creative. Malang

Jogiyanto .2016. Teori Portofolio Dan Analisis Investasi. Edisi Tiga. Yogyakarta: DPFE UGM. 